\title{
Cesium-131 brachytherapy for recurrent brain metastases: durable salvage treatment for previously irradiated metastatic disease
}

\author{
${ }^{*}$ A. Gabriella Wernicke, MD, MSc, ${ }^{1}$ Andrew W. Smith, BA, ${ }^{2}$ Shoshana Taube, BA, ${ }^{1}$ \\ Menachem Z. Yondorf, MS, ${ }^{1}$ Bhupesh Parashar, MD, ${ }^{1}$ Samuel Trichter, MS, ${ }^{1}$ Lucy Nedialkova, PhD, ${ }^{1}$ \\ Albert Sabbas, PhD, ${ }^{1}$ Paul Christos, DrPH, MS, ${ }^{3}$ Rohan Ramakrishna, MD, ${ }^{4}$ \\ Susan C. Pannullo, MD, ${ }^{4}$ Philip E. Stieg, PhD, MD, ${ }^{4}$ and Theodore H. Schwartz, MD ${ }^{4}$
}

\begin{abstract}
${ }^{1}$ Stich Radiation Oncology Center, ${ }^{3}$ Division of Biostatistics and Epidemiology, Department of Healthcare Policy and Research, and ${ }^{4}$ Department of Neurosurgery, Weill Medical College of Cornell University, New York; and 2University of Rochester School of Medicine and Dentistry, Rochester, New York
\end{abstract}

\begin{abstract}
OBJECTIVE Managing patients whose intraparenchymal brain metastases recur after radiotherapy remains a challenge. Intraoperative cesium-131 (Cs-131) brachytherapy performed at the time of neurosurgical resection may represent an excellent salvage treatment option. The authors evaluated the outcomes of this novel treatment with permanent intraoperative Cs-131 brachytherapy.
\end{abstract}

METHODS Thirteen patients with 15 metastases to the brain that recurred after stereotactic radiosurgery and/or whole brain radiotherapy were treated between 2010 and 2015. Stranded Cs-131 seeds were placed as a permanent volume implant. Prescription dose was $80 \mathrm{~Gy}$ at 5-mm depth from the resection cavity surface. The primary end point was resection cavity freedom from progression (FFP). Resection cavity freedom from progression (FFP), regional FFP, distant FFP, median survival, overall survival (OS), and toxicity were assessed.

RESULTS The median duration of follow-up after salvage treatment was 5 months (range $0.5-18$ months). The patients' median age was 64 years (range 51-74 years). The median resected tumor diameter was $2.9 \mathrm{~cm}$ (range 1.0-5.6 cm). The median number of seeds implanted was 19 (range 10-40), with a median activity per seed of $2.25 \mathrm{U}$ (range 1.98$3.01 \mathrm{U}$ ) and median total activity of $39.6 \mathrm{U}$ (range 20.0-95.2 U). The 1-year actuarial local FFP was 83.3\%. The median OS was 7 months, and 1-year OS was $24.7 \%$. Complications included infection (3), pseudomeningocele (1), seizure (1), and asymptomatic radionecrosis (RN) (1).

CONCLUSIONS After failure of prior irradiation of brain metastases, re-irradiation with intraoperative Cs-131 brachytherapy implants provides durable local control and limits the risk of RN. The authors' initial experience demonstrates that this treatment approach is well tolerated and safe for patients with previously irradiated tumors after failure of more than 1 radiotherapy regimen and that it results in excellent response rates and minimal toxicity.

https://thejns.org/doi/abs/10.3171/2016.3.JNS152836

KEY WORDS cesium-131; brachytherapy; metastases; recurrence; radiation; re-irradiation; oncology

$\mathrm{P}$ ATIENTS with brain metastases are experiencing longer survival times because of earlier detection ${ }^{36}$ and more effective treatment ${ }^{30}$ of these lesions as well as improved therapies for extracranial disease. ${ }^{11}$ This increase in longevity results in an increased frequency of tumor recurrences following surgical and/or radiation therapy. Upon recurrence, previously irradiated patients frequently undergo a maximally safe neurosurgical resection followed by the addition of adjuvant radiotherapy to en- sure local control of the resected recurrent metastasis. Adjuvant radiation options include whole brain radiotherapy (WBRT) ${ }^{20,21,23,24,44}$ postoperative stereotactic radiosurgery (SRS), $4,16,18,26-28,30,31,52$ or intraoperative brachytherapy with either permanent radioisotopes such as cesium-131 (Cs$131)^{55}$ or iodine- 125 (I-125) $)^{6,13,25,48}$ or temporary high-dose I-125, 5,39,42,47 WBRT exposes larger brain volumes to radiation, which can increase the risk of neurocognitive toxicities. ${ }^{7}$ Therefore, focal radiation techniques such as SRS

ABBREVIATIONS ADC = apparent diffusion coefficient; FFP = freedom from progression; $O S$ = overall survival; $Q O L=$ quality of life; $R N=$ radionecrosis; $R P A=$ recursive partitioning analysis; SRS = stereotactic radiosurgery; WBRT = whole brain radiotherapy. SUBMITTED December 4, 2015. ACCEPTED March 4, 2016. INCLUDE WHEN CITING Published online June 3, 2016; DOI: 10.3171/2016.3.JNS152836.

* Dr. Wernicke and Mr. Smith contributed equally to this work. 
are generally favored. Nevertheless, the efficacy of SRS is limited for larger tumors because of a significantly greater risk of failure and unacceptable CNS toxicity. According to the Radiation Therapy Oncology Group (RTOG) 90-05 trial, compared with treatment of tumors $\leq 2.0 \mathrm{~cm}$ in diameter, treatment of tumors measuring $2.1-3.0 \mathrm{~cm}$ is associated with a 7.3 times higher risk and treatment of 3.1- to $4.0-\mathrm{cm}$ tumors with a 16.0 times higher risk of irreversible severe, life threatening, or fatal CNS toxicity. ${ }^{49}$

Another disadvantage of further re-irradiation in the salvage setting is the limited lifetime tolerance of brain tissue to radiation, resulting in a cumulative risk of radionecrosis $(\mathrm{RN})$. Indeed, even in the setting of newly diagnosed brain metastasis, the tradeoff to achieving a durable local control with either intraoperative I-125 or postoperative radiotherapy (SRS or WBRT) has been the high rates of $\mathrm{RN} .5,6,13,25,39,42,47,48,59$ A novel radioisotope, Cs-131, renders both physical and radiobiological advantages as compared with postoperative SRS or I-125 brachytherapy. Cs-131 has been shown to achieve excellent rates of local control and negligible rates of $\mathrm{RN}$ in a recently published prospective trial of newly diagnosed brain metastases. ${ }^{55}$ In the present study, we evaluated this novel treatment approach with permanent intraoperative Cs-131 brachytherapy as salvage therapy for previously irradiated recurrent brain metastases.

\section{Methods \\ Patient Selection}

The records of patients who underwent surgery for previously irradiated recurrent brain metastases and were treated with intraoperative Cs-131between 2010 and 2015 were reviewed after institutional review board approval. Selection criteria for such treatment included a metastatic tumor with surgery indicated for diagnostic purposes, to relieve mass effect, reduce symptoms, or based on lesion size $>2.5 \mathrm{~cm}$. Patients had Eastern Cooperative Oncology Group (ECOG)/Zubrod Performance Status 0, 1, or 2 and expected survival $\geq 6$ months. Patients with tumor proximity to the optic chiasm or brainstem, small cell cancer histology metastatic to the brain, pregnancy, or unwillingness to practice a form of birth control were not selected for this treatment.

\section{Treatment Technique}

Patients underwent maximal safe neurosurgical resection of lesions. The extent of resection along with tumor size, location, and pial involvement were noted. At the time of resection, stranded Cs-131 seeds (IsoRay) with an activity of 3-5 mCi were implanted, with a planned dose of $\mathrm{D}_{90}$ to receive 80 Gy to a $5-\mathrm{mm}$ depth from the surface of the resection cavity. The therapeutic dose of the implant was calculated based on preoperative data on tumor size and our institutional physics nomogram, and it was adjusted in real time for the intracavitary volume after resection of the metastasis. The $10-\mathrm{cm}$ suture-stranded Cs-131 seeds, with $0.5-\mathrm{cm}$ interseed spacing, were delivered in strings of 10 seeds per string, cut into smaller lengths as per the nomogram, and placed as a permanent volume implant along the cavity in a tangential pattern to maintain 7 - to $10-\mathrm{mm}$ spacing between strands. Thus, the cavity was lined like "barrel staves" or "parallel tracks." The seeds were then covered with Surgicel (Ethicon) to prevent seed migration and alteration of dosimetry. Tisseel (Baxter) was then used to line the cavity to limit cavity shrinkage and to further prevent seed dislodgement. ${ }^{54}$ The patient underwent a postimplant CT scan within $24-48$ hours after surgery to determine dose distribution. The conformity index was calculated at that time according to Paddick's formula. ${ }^{43}$

\section{Follow-Up}

The duration of follow-up was defined by the number of months between implant and a patient's last follow-up visit, as determined by the patient's medical record. Follow-up examinations included MRI every 2 months. At the time of disease progression elsewhere in the brain, the metastases were treated with SRS or WBRT, depending on the number of lesions. RN was defined based on review of follow-up MRI for contrast enhancement and diffusion restriction by a neuroradiologist, and concerning scans were also reviewed by the treatment team.

\section{End Points and Statistical Methods}

The primary focus of this analysis was local resection cavity freedom from progression (FFP). Secondary analyses included regional FFP and distant FFP, median survival, overall survival (OS), and toxicity. Treatment response was evaluated from follow-up brain MR images as compared with the prior MR images. Local FFP was defined as the absence of new nodular contrast enhancement $\leq 5 \mathrm{~mm}$ from the resection cavity, regional failure was defined as new or increased contrast enhancement $>5$ $\mathrm{mm}$ from the resection cavity, and distant failure was defined as new or increased contrast enhancement elsewhere in the brain. All survival end points were defined as the time from the date of resection and Cs-131 implantation until either the date of local recurrence (for local FFP), the date of regional recurrence (for regional FFP), the date of new metastasis (for distant FFP), or the date of death (for OS). Patients without these events were censored at their date of last follow-up. Kaplan-Meier survival analysis was performed to generate survival curves. Median and 1-year local FFP, regional FFP, distant FFP, and OS were estimated, and 95\% confidence intervals (CIs) were calculated. All analyses were performed using SPSS version 23.0 (SPSS Inc.) and STATA version 14.0 (StataCorp).

\section{Results \\ Patient Characteristics}

Thirteen patients with 15 brain metastases were included in this study. Patient demographics and baseline characteristics are summarized in Table 1. The treated brain metastases were located in the frontal (3), parietal (4), cerebellar (2), insular (1), occipital (2), and temporal (3) regions. The histology from the metastases were lung (9), breast (1), melanoma (3), gastric (1), and pancreatic (1). The 6 patients who were classified as recursive partitioning analysis (RPA) Class 2 were all receiving systemic therapy for their primary disease and were offered WBRT for their brain metastasis, but all refused and wished to proceed with local therapy. Of the remaining 7 patients, 
who were classified as RPA Class 1, 5 patients were not being treated for primary disease because it was controlled, 1 was stable on trastuzumab therapy for breast cancer, and 1 received stereotactic body radiotherapy with clinical response for recurrent lung cancer 4 months before receiving brain brachytherapy.

\section{Treatment Parameters}

Details of the resections and Cs-131 implants are shown in Table 2. Maximally safe neurosurgical resection and Cs-131 brachytherapy implantation was performed for all 15 lesions, and gross-total resection (defined as resection of contrast enhancing disease) was achieved for 14 lesions. The patient who underwent a subtotal resection received SRS of 24 Gy in 3 fractions to the residual tumor just posterior to the resection cavity 2 months after receiving brachytherapy. At the time of brachytherapy, 3 patients had additional metastases that were treated with SRS alone. Based on the preoperative MRI, the median diameter of the resected tumors was $2.9 \mathrm{~cm}$ (range 1.0-5.6 $\mathrm{cm})$. Based on intraoperative measurements, the median volume of the cavity after tumor resection was $3.13 \mathrm{~cm}^{3}$ (range 1-17 $\mathrm{cm}^{3}$ ), indicating a $69.6 \%$ decrease in cavity volume before the seeds were placed. The median number of seeds employed was 19 (range 10-40), with median activity per seed of $2.25 \mathrm{U}$ (range 1.98-3.01 U) and a median total activity of $39.6 \mathrm{U}$ (range 20.0-95.2 U). The median conformity index was 0.65 (range $0.4-0.7$ ).

\section{Survival}

At the time of analysis, 4 patients were still alive, 3 with primary lung cancer and 1 with primary gastric cancer. The median duration of follow-up subsequent to salvage treatment was 5 months for the whole cohort (range 0.6-18 months). Five lesions were previously treated with both WBRT and SRS, and 10 lesions were previously treated with SRS. Among the 9 patients who died, there were 4 with primary lung cancer, 3 with melanoma, 1 with breast cancer, and 1 with pancreatic cancer. Five patients died of complications of their systemic disease. One patient died of infection, and 1 patient with a history of seizures had a seizure, aspirated, and died of pneumonia 2 weeks after surgery; the cause of death could not be determined for 2 patients. The median OS was 7 months from the date of salvage therapy (95\% CI 4-14.8 months). The actuarial 1-year OS was $24.7 \%$ (95\% CI $4.2 \%-54.0 \%$ ) (Fig. 1, Table 3).

\section{Freedom From Progression}

There was 1 case of local recurrence within $5 \mathrm{~mm}$ of the resection cavity (in a patient with a frontal lobe lesion). This yielded a local recurrence 1-year FFP of 83.3\% (95\% CI 27.3\%-97.5\%). Two cases of regional recurrence yielded a 1-year regional FFP of 55.6\% (95\% CI 7.3\%$87.6 \%$ ). There were 3 patients with distant metastases, which yielded a median distant FFP of 11 months (95\% CI 5 months, upper limit not estimated) and a 1-year distant FFP of $46.7 \%$ (95\% CI 7.1\%-80.3\%) (Fig. 2, Table 3). Distant progression was treated with either WBRT or SRS, and 1 patient died before treatment.
TABLE 1. Patient demographics and baseline characteristics*

\begin{tabular}{|c|c|}
\hline Variable & Value \\
\hline \multicolumn{2}{|l|}{ Sex } \\
\hline M & $5(38)$ \\
\hline $\mathrm{F}$ & $8(53)$ \\
\hline No. of metastases treated & 15 \\
\hline \multicolumn{2}{|l|}{ Age at prior RT in yrs } \\
\hline Median & 68 \\
\hline Range & $47-74$ \\
\hline \multicolumn{2}{|l|}{ RPA class } \\
\hline 1 & $7(54)$ \\
\hline 2 & $6(46)$ \\
\hline \multicolumn{2}{|l|}{ Prior RT } \\
\hline SRS only & $8(62)$ \\
\hline SRS+WBRT & $5(38)$ \\
\hline \multicolumn{2}{|l|}{ Mode of delivery of SRS } \\
\hline LINAC-based & $4(31)$ \\
\hline CyberKnife & $1(8)$ \\
\hline Gamma Knife & $7(54)$ \\
\hline \multicolumn{2}{|l|}{ Metastases treated } \\
\hline Intact & $12(80)$ \\
\hline Resected cavity & $3(20)$ \\
\hline \multicolumn{2}{|l|}{ Tumor location } \\
\hline Frontal & $3(20)$ \\
\hline Parietal & $4(27)$ \\
\hline Cerebellar & $2(13)$ \\
\hline Insular & $1(7)$ \\
\hline Occipital & $2(13)$ \\
\hline Temporal & $3(20)$ \\
\hline \multicolumn{2}{|l|}{ Tumor pathology } \\
\hline Lung & $9(60)$ \\
\hline Breast & $1(7)$ \\
\hline Pancreatic & $1(7)$ \\
\hline Gastric & $1(7)$ \\
\hline Melanoma & $3(20)$ \\
\hline
\end{tabular}

LINAC = linear accelerator; RT = radiation therapy.

* Values are number (\%) unless otherwise indicated.

\section{Complications}

Postoperatively, the patients were treated with $4 \mathrm{mg}$ of dexamethasone twice a day for 2 weeks. There was 1 instance of asymptomatic T1 signal enhancement and elevated apparent diffusion coefficient (ADC) around the surgical cavity on FLAIR MRI 5 months after seed implantation that was classified as RN. Additional complications included 3 infections, 1 seizure, and 1 pseudomeningocele. Overall, $46 \%$ of patients experienced a complication.

\section{Discussion}

This study demonstrates that intraoperative brachytherapy with Cs-131 can be delivered as successful salvage therapy for recurrent brain metastases. While a seed activity of $2.4 \mathrm{U}$ is generally used to treat newly diagnosed 
TABLE 2. Salvage of previously irradiated metastases with neurosurgery and Cs-131 intraoperative application

\begin{tabular}{|c|c|c|c|c|c|c|c|c|c|c|c|c|}
\hline \multirow[b]{2}{*}{$\begin{array}{l}\text { Metastasis } \\
\text { No. }\end{array}$} & \multirow{2}{*}{$\begin{array}{l}\text { Pathology } \\
\text { of Recurrent } \\
\text { Metastasis }\end{array}$} & \multirow{2}{*}{$\begin{array}{l}\text { Months to } \\
\text { Recurrence } \\
\text { from Prior } \\
\text { RT }\end{array}$} & \multicolumn{2}{|c|}{$\begin{array}{l}\text { Tumor Diameter on } \\
\text { MRI }(\mathrm{cm})\end{array}$} & \multirow{2}{*}{$\begin{array}{c}\text { Type } \\
\text { of } \\
\text { Prior RT }\end{array}$} & \multirow[b]{2}{*}{ Laterality } & \multirow[b]{2}{*}{$\begin{array}{l}\text { Location of } \\
\text { Recurrence }\end{array}$} & \multirow{2}{*}{$\begin{array}{c}\text { No. of } \\
\text { Cs-131 } \\
\text { Seeds } \\
\text { Implanted }\end{array}$} & \multicolumn{2}{|c|}{$\begin{array}{c}\text { Seed } \\
\text { Activity }\end{array}$} & \multicolumn{2}{|c|}{$\begin{array}{c}\text { Total } \\
\text { Activity }\end{array}$} \\
\hline & & & $\begin{array}{l}\text { Initial } \\
\text { Lesion }\end{array}$ & $\begin{array}{l}\text { Recurrent } \\
\text { Lesion }\end{array}$ & & & & & U & $\mathrm{mCi}$ & U & $\mathrm{mCi}$ \\
\hline 1 & Melanoma & 10 & 3.4 & 2.7 & SRS+WBRT & Rt & Parietal & 12 & 3.01 & 4.72 & 36.12 & 56.64 \\
\hline 2 & Lung & 17 & 2.5 & 4.8 & SRS+WBRT & $\mathrm{Rt}$ & Cerebellar & 27 & 2.26 & 3.55 & 61.02 & 95.85 \\
\hline 3 & Melanoma & 16 & 2.3 & 4.2 & SRS & $\mathrm{Lt}$ & Insular & 29 & 2.24 & 3.52 & 31.36 & 102.08 \\
\hline 4 & Melanoma & 15 & 2.8 & 2.8 & SRS & $\mathrm{Rt}$ & Parietal & 14 & 2.81 & 4.41 & 66.15 & 61.74 \\
\hline 5 & Lung & 18 & 3.6 & 3.1 & SRS+WBRT & $\mathrm{Lt}$ & Frontal & 19 & 2.36 & 3.71 & 49.56 & 70.49 \\
\hline 6 & Breast & 26 & 1.1 & 2.6 & SRS & Rt & Frontal & 10 & 2.00 & 3.14 & 20.00 & 31.40 \\
\hline 7 & Lung & 13 & 1.4 & 2.7 & SRS+WBRT & Rt & Parietal & 13 & 1.99 & 3.12 & 25.87 & 40.56 \\
\hline 8 & Lung & 15 & 2.4 & 2.9 & SRS & $\mathrm{Lt}$ & Cerebellar & 10 & 2.804 & 4.4 & 28.04 & 44.00 \\
\hline 9 & Lung & 14 & 3.4 & 5.6 & SRS+WBRT & $\mathrm{Lt}$ & Temporal & 40 & 2.38 & 3.73 & 95.20 & 149.20 \\
\hline 10 & Lung & 12 & 1.5 & 3.9 & SRS & $\mathrm{Lt}$ & Parietal & 24 & 2.24 & 3.52 & 58.08 & 84.48 \\
\hline 11 & Lung & 19 & UN & 1.0 & SRS & $\mathrm{Lt}$ & Occipital & 11 & 2.21 & 3.47 & 24.31 & 38.17 \\
\hline 12 & Gastric & 3 & UN & 3.2 & SRS & $\mathrm{Lt}$ & Occipital & 30 & 2.39 & 3.76 & 71.83 & 112.8 \\
\hline 13 & Pancreatic & 16 & UN & 2.7 & SRS & $\mathrm{Lt}$ & Temporal & 16 & 2.00 & 3.14 & 32.00 & 50.24 \\
\hline 14 & Lung & 3 & 2.5 & 3.2 & SRS & $\mathrm{Lt}$ & Frontal & 20 & 1.98 & 3.10 & 39.60 & 62.00 \\
\hline 15 & Lung & 3 & 1.3 & 1.6 & SRS & $\mathrm{Lt}$ & Temporal & 20 & 1.98 & 3.10 & 39.60 & 62.00 \\
\hline
\end{tabular}

$\mathrm{UN}=$ unknown.

brain metastases, we used a lower median activity level of $2.25 \mathrm{U}$ in the salvage setting to take into account previous irradiation and avoid complications associated with cumulative toxicity. However, our first patient was treated with $3.01 \mathrm{U}$ activity per seed and developed mild asymptomatic RN, evident on MRI 5 months after surgery, and was treated with dexamethasone. ADC around the cavity in this patient was $1.43 \mathrm{~mm}^{2} / \mathrm{sec}$ compared with a contralateral white matter ADC of $0.84 \mathrm{~mm}^{2} / \mathrm{sec}$. When he was lost to follow-up 7 months after surgery, his steroid dosage was being tapered and he remained asymptomatic. Learning from this experience, we lowered the seed activity, and thus later patients were treated with lower seed activity levels. We found that this approach avoided significant postoperative edema or RN and still provided excellent rates of local control.

Improved survival in patients with metastatic brain disease may be accompanied by more frequent local relapse requiring treatment and management of recurrent brain metastases. Salvage therapy options include resection alone or resection followed by adjuvant therapy (SRS or WBRT), repeat SRS, WBRT, and resection with intraoperative brachytherapy. In most cases, surgery alone has been shown to be insufficient as salvage treatment. Re-irradiation presents a tremendous challenge, as it raises legitimate concerns of exceeding tissue tolerance to radiation and inducing $\mathrm{RN} .{ }^{17,23} \mathrm{WBRT}$, while reducing the rates of recurrence to $10 \%-20 \%$, decreases quality of life (QOL) and produces neurocognitive deficits. ${ }^{7,10,12,15,32,40}$ For this reason, attention has been turned to using focal radiation in the form of SRS or brachytherapy in patients requiring salvage for brain metastases (Table 4).

The use of SRS as salvage therapy has been increasing, and several institutions have adopted this technique as a new standard of care. Crude local control rates range from $60 \%-87 \% \%^{8,22,50,51}$ with 1-year actuarial local control rates of $60 \%-91 \%$ at 1 year. $8,33,37,41,58$ The ideal target for SRS is a small round cavity, and tumor cavities of irregular shape or larger size $(>2 \mathrm{~cm})$ present a challenge in developing a treatment plan with a high degree of conformality. Indeed, it has been shown that larger tumor cavities treated with postoperative SRS have poor local control resulting from less conformal treatment plans. ${ }^{9}$ Moreover, in patients irradiated with SRS, the volume of irradiated tissue is a clear predictor of symptomatic RN.,40 For this reason, brachytherapy may have a role in treating large or irregularly shaped recurrent tumors. Our median tumor cavity diameter of $2.9 \mathrm{~cm}$ is significantly larger than median cavities reported in most SRS studies, and yet our local control rate is comparable. Furthermore, with no instances of symptomatic RN, brachytherapy with Cs-131 is superior when compared with the entire cohort in the above SRS studies. When examining those studies that provide outcomes and side effects data for tumors $>2 \mathrm{~cm}$, the poorer rates of local control $\left(91 \%\right.$ vs $62 \%$ at 1 year $\left.^{8}\right)$ and higher rates of RN (1.6\% vs $\left.7 \%{ }^{37}\right)$ in this cohort compared with smaller tumors makes the benefits of Cs-131 brachytherapy even more apparent.

Brachytherapy allows a high dose of radiation to be given to a localized area with a very steep dose fall-off, thus covering an irregular tumor bed but sparing adjacent normal brain tissue. ${ }^{34,38}$ A conformity index $\geq 0.8$, as described by Paddick, is known to be associated with local failure on multivariate analysis in 1 study of patients treated with SRS. ${ }^{56}$ The authors of that study hypothesize that these data support the rationale for surgery followed by radiotherapy delivered to the cavity for treatment of brain metastases. All of our patients had a conformity index below 0.8 , although our 1 patient with local recurrence had a conformity index of 0.7 .

Having a very steep dose fall-off is a feature that makes brachytherapy a rather attractive option in patients requir- 


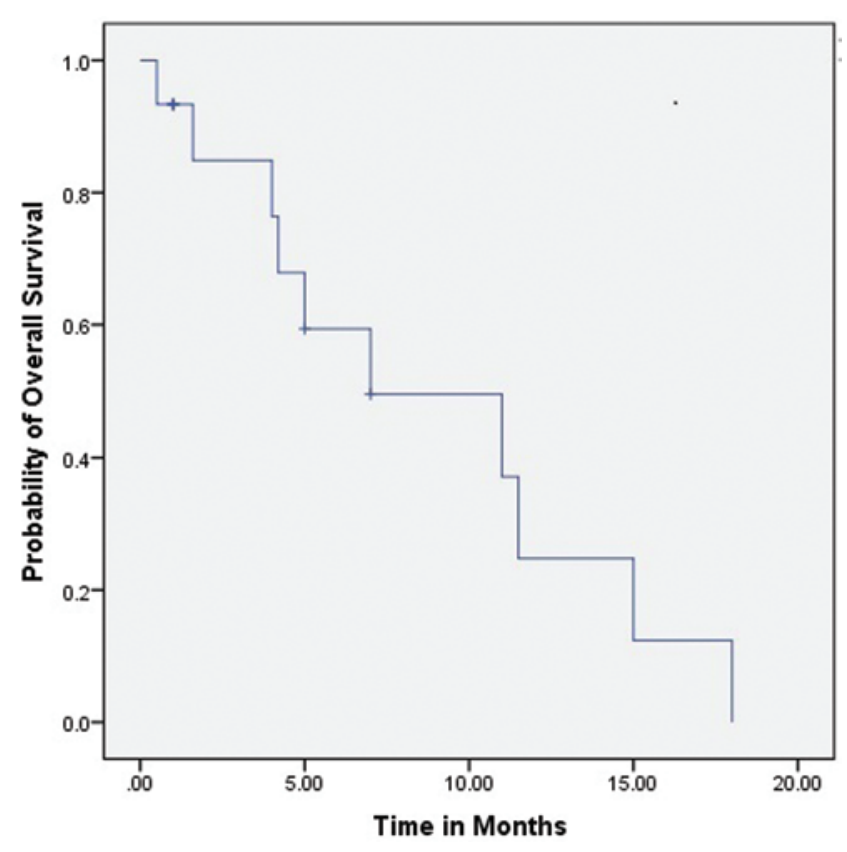

FIG. 1. Kaplan-Meier plot showing OS. Figure is available in color online only.

ing salvage therapy, as it may avoid causing $\mathrm{RN}$ in a brain previously exposed to radiation. Brachytherapy is also more cost-effective than WBRT or SRS. ${ }^{53}$ Furthermore, in those patients receiving surgery as initial salvage therapy, there is a radiobiological advantage to administering immediate radiotherapy so as to preclude cancer cell repopulation, which typically occurs at approximately 4 weeks after resection. Continuous dose rate radiation of brachytherapy at $0.3-3.5 \mathrm{~Gy} / \mathrm{hr}$ inhibits mitosis and causes proliferating tumor cells to accumulate in $\mathrm{G} 2$, a radiosensitive phase of the cell cycle. ${ }^{20}$ There is less radioresistance of hypoxic cells treated with brachytherapy due to impaired repair of sublethal damage under hypoxic conditions ${ }^{35}$ and the opportunity for hypoxic cells to become re-oxygenated during the treatment. ${ }^{20}$

Criticisms of brachytherapy have focused on the high rates of $\mathrm{RN}$ reported in some series where the modality was used to treat newly diagnosed metastases. These series involved a stereotactic biopsy followed by permanent high-dose implants ${ }^{25}$ and treatment was performed for recurrent lesions refractory to $\mathrm{WBRT}^{5,48}$ or administered concurrent WBRT. ${ }^{58}$ The use of brachytherapy for local control of newly resected metastases without WBRT has been reported more recently. In those series, RN was more common with the use of high-dose temporary brachytherapy, such as the Glia Site balloon, and was reported to occur at a rate of $23 \% .{ }^{47}$ In the continuous low-dose permanent brachytherapy setting, $0 \%$ rates of $\mathrm{RN}$ were shown by Bogart et al., who used I-125 seeds with activity $0.32-0.45 \mathrm{mCi}$ and a cumulative dose of 80-160 Gy using a median of 13 seeds ${ }^{6,46}$ but achieved a local control of only $80 \%$. Huang et al. reported a $21 \%$ rate of RN in their newly diagnosed cohort using a median of 35 I-125 seeds, with a median activity of $0.30 \mathrm{mCi}$ and median dose 800 Gy to the surface (200 Gy to a depth of $1 \mathrm{~cm}$ ), yielding a reported local control of $92 \% .{ }^{25}$ These data indicate that a
TABLE 3. Survival and freedom from progression end points*

\begin{tabular}{lc}
\hline \multicolumn{1}{c}{ End Point } & Value \\
\hline No. of deaths & $10(66.7 \%)$ \\
\hline Median survival time in mos & 7 \\
\hline 1-yr OS $(95 \% \mathrm{Cl})$ & $24.7 \%(4.2-54.0 \%)$ \\
\hline No. of local failures & $1(6.7 \%)$ \\
\hline 1-yr local FFP $(95 \% \mathrm{Cl})$ & $83.3 \%(27.3-97.5 \%)$ \\
\hline No. of regional failures & $2(13.3 \%)$ \\
\hline 1-yr regional FFP $(95 \% \mathrm{Cl})$ & $55.6 \%(7.3-87.6 \%)$ \\
\hline No. of distant failures & $3(20 \%)$ \\
\hline 1-yr distant FFP $(95 \% \mathrm{Cl})$ & $46.7 \%(7.1-80.3 \%)$ \\
\hline * Kaplan-Meier survival analysis was performed to generate survival values.
\end{tabular}

lower seed activity coupled with a lower prescription dose will decrease the rate of RN with only a minimal impact on local control.

We carefully took into account the aforementioned information while designing treatment with Cs-131 so as to minimize the incidence of $\mathrm{RN}$ in this high-risk population. The lowered seed activity of Cs-131 and dose prescription in our study did not only achieve a high rate of local control but resulted in no occurrences of symptomatic RN, which compares favorably to published studies of salvage therapy for brain metastases (Table 4). It should be noted that distinguishing $\mathrm{RN}$ from pseudoprogression or recurrence on imaging remains a challenge. Because ADC is inversely correlated with tumor cellularity, several studies have proposed using diffusion-weighted imaging techniques to address this problem, and we have used this approach in our current study in the absence of any cases requiring re-resection that would have allowed pathological differentiation. ${ }^{9}$

The rationale behind employing Cs-131 instead of I-125 lies in several physical and radiobiological advantages of Cs-131. The high mean energy of Cs-131 of $29 \mathrm{keV}$ allows fewer radioactive seeds to be implanted per given volume. Additionally, whereas I-125 has a dose rate of $0.069 \mathrm{~Gy} /$ hr, Cs-131 has a higher dose rate of $0.342 \mathrm{~Gy} / \mathrm{hr}$. In essence, this means that after implantation with Cs-131, $90 \%$ of the dose is absorbed in 33 days, in contrast with only $32 \%$ of the dose absorption that occurs with I-125 in the same time period. This short half-life of 9.69 days (compared with 59.4 days for I-125) ensures a shorter average life of the radioactive seed. Should systemic therapy be started after seed implantation, the short half-life of Cs131 limits the time during which the patient is exposed to both radiation and systemic therapy, thereby potentially minimizing overlap in treatment-related toxicities. Furthermore, because cavity shrinkage, a poorly understood process that progressively moves the seeds closer together over time, , $14,29,57$ complicates the use of brachytherapy, a larger fraction of total dose delivered in the early period after surgery spares more normal tissue from exposure to radiation. Our group found a nonsignificant decrease in cavity volume in the 1st month after surgery, the period when the vast majority of Cs-131 dose is delivered. ${ }^{54} \mathrm{An}$ isotope with a longer half-life, such as I-125, would continue to deliver a significant dose longer after surgery, when 

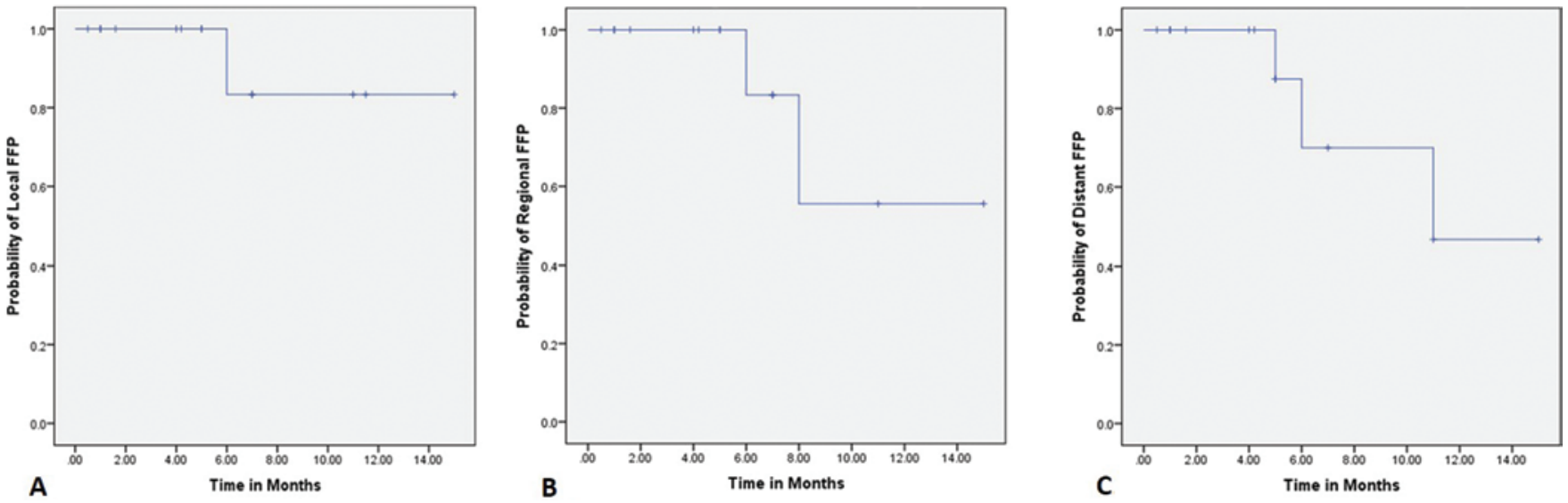

FIG. 2. Kaplan-Meier plots showing local FFP (A), regional FFP (B), and distant FFP (C). Figure is available in color online only.

the impact of changing cavity dynamics might be more significant.

We undertook several measures to decrease the degree of cavity shrinkage once the seeds were placed. The seeds were not placed individually but were attached by strings with tensile strength. These strings lined the cavity like barrel staves, maintaining a certain amount of outward pressure on the cavity to keep it from collapsing. Likewise, fibrin glue was placed over the seeds, not only to keep them from moving but to create additional outward pressure on the cavity to prevent cavity shrinkage. ${ }^{54}$ Since the majority of the mass effect of the tumor bulk was relieved after the initial surgery, indicated by the $69.6 \%$ shrinkage in cavity volume prior to seed placement, the maintenance of a smaller residual volume during the treatment period did not compromise the surgical goal of relieving mass effect.

The success of intracavitary brachytherapy and the low rates of RN must be tempered by the increased rate of complications. Wound healing, infection, and seizure are not trivial issues in these patients and can impact their overall survival as well as their QOL. Our series included 3 patients with postoperative infections; however, their re-

TABLE 4. Comparison of published salvage modalities for previously irradiated recurrent brain metastases

\begin{tabular}{|c|c|c|c|c|c|}
\hline Author \& Year & $\begin{array}{l}\text { Salvage } \\
\text { Modality }\end{array}$ & $\begin{array}{c}\text { Median } \\
\text { Treatment } \\
\text { Dose (Gy) }\end{array}$ & $\begin{array}{l}\text { No. of } \\
\text { Treated } \\
\text { Lesions }\end{array}$ & $\begin{array}{l}1-Y r \\
\text { LC } \\
\text { Rate } \\
(\%)\end{array}$ & $\begin{array}{c}\text { Rate } \\
\text { of RN } \\
\text { Requiring } \\
\text { Reop (\%) }\end{array}$ \\
\hline $\begin{array}{l}\text { Maranzano et } \\
\text { al., } 2012\end{array}$ & SRS & 20 & 69 & 74 & 3 \\
\hline Chao et al., 2008 & SRS & 23.6 & 111 & 68 & 1.8 \\
\hline Kurtz et al., 2014 & SRS & 21 & 106 & 60.1 & 3.8 \\
\hline $\begin{array}{l}\text { Yomo \& Hayashi, } \\
2013\end{array}$ & SRS & 20 & 77 & 76.6 & 3.9 \\
\hline $\begin{array}{l}\text { Huang et al., } \\
2009\end{array}$ & $\begin{array}{l}\text { Perm } \\
\text { I-125 }\end{array}$ & $300^{*}$ & 21 & 86 & 9.5 \\
\hline Present study & $\begin{array}{l}\text { Perm } \\
\quad \text { Cs-131 }\end{array}$ & $80^{*}$ & 15 & 83.3 & 0 \\
\hline
\end{tabular}

$\mathrm{LC}=$ local control; Perm = permanent.

* Dose at 5-mm distance. operations were not straightforward. The first patient had undergone 2 prior craniotomies and 2 prior radiation treatments and was HIV positive, with a CD4+ count of 413 shortly before surgery. The second patient had undergone 4 prior craniotomies and 6 prior radiation treatments, and the third had undergone 2 prior craniotomies and 2 prior radiation treatments. Hence, these were multiply recurrent tumors. There are very little data on the risk of infection in patients who are having their third or even fifth craniotomies with multiple radiation treatments in between, and, undoubtedly, the rates are higher than for patients undergoing their first or even second operations. Additionally, CD4+ counts below 500 have been reported to be independently associated with higher rates of surgical wound infections. ${ }^{1}$ Nevertheless, in these patients, we recommend the following maneuvers to decrease the rate of postoperative infection. The bone and wound should be irrigated with Betadine and vancomycin powder before closure, in addition to standard antibiotic irrigation, and a plastic surgeon should assist with wound closure. ${ }^{2,19,45}$ These risks must be balanced with the impact of treatment on survival and progression-free survival, and open conversations with patients are essential for choosing the best treatment on an individual basis.

\section{Limitations}

In this analysis, we report results of the initial 15 recurrent metastases. More substantial numbers of patients from other institutions treated in a similar manner will be required to make more definitive conclusions. Also, a prospective trial for Cs-131 brachytherapy in the salvage setting is indicated. Finally, formal objective measures of QOL and cognitive processing as well as cost will help in comparing Cs-131 brachytherapy with other treatment options.

\section{Conclusions}

This is the first report of patients with recurrent and previously irradiated brain metastases treated with maximally safe neurosurgical resection and re-irradiation with intraoperative application of Cs-131. To date, this method of brachytherapy, based on our institutional nomogram and surgical technique, has rendered excellent local control and a low toxicity profile. 


\section{Acknowledgments}

Dr. Paul Christos was partially supported by a grant from the Clinical Translational Science Center (CTSC) (UL1TR000457-06).

\section{References}

1. Abalo A, Patassi A, James YE, Walla A, Sangare A, Dossim A: Risk factors for surgical wound infection in HIV-positive patients undergoing surgery for orthopaedic trauma. J Orthop Surg (Hong Kong) 18:224-227, 2010

2. Abdullah KG, Attiah MA, Olsen AS, Richardson A, Lucas $\mathrm{TH}$ : Reducing surgical site infections following craniotomy: examination of the use of topical vancomycin. J Neurosurg 123:1600-1604, 2015

3. Atalar B, Choi CY, Harsh GR IV, Chang SD, Gibbs IC, Adler JR, et al: Cavity volume dynamics after resection of brain metastases and timing of postresection cavity stereotactic radiosurgery. Neurosurgery 72:180-185, 2013

4. Beal K, Chan K, Chan T, Yamada Y, Narayana A, Lymberis $\mathrm{S}$, et al: A Phase II prospective trial of stereotactic radiosurgery boost following surgical resection for brain metastases. Int J Radiat Oncol Biol Phys 75 Suppl:S126-S127, 2009 (Abstract)

5. Bernstein M, Cabantog A, Laperriere N, Leung P, Thomason C: Brachytherapy for recurrent single brain metastasis. Can J Neurol Sci 22:13-16, 1995

6. Bogart JA, Ungureanu C, Shihadeh E, Chung TC, King GA, Ryu S, et al: Resection and permanent I-125 brachytherapy without whole brain irradiation for solitary brain metastasis from non-small cell lung carcinoma. J Neurooncol 44:5357, 1999

7. Chang EL, Wefel JS, Hess KR, Allen PK, Lang FF, Kornguth DG, et al: Neurocognition in patients with brain metastases treated with radiosurgery or radiosurgery plus whole-brain irradiation: a randomised controlled trial. Lancet Oncol 10:1037-1044, 2009

8. Chao ST, Barnett GH, Vogelbaum MA, Angelov L, Weil RJ, Neyman G, et al: Salvage stereotactic radiosurgery effectively treats recurrences from whole-brain radiation therapy. Cancer 113:2198-2204, 2008

9. Chen L, Liu M, Bao J, Xia Y, Zhang J, Zhang L, et al: The correlation between apparent diffusion coefficient and tumor cellularity in patients: a meta-analysis. PLoS ONE 8:e79008, 2013

10. Chow E, Davis L, Holden L, Tsao M, Danjoux C: Prospective assessment of patient-rated symptoms following whole brain radiotherapy for brain metastases. J Pain Symptom Manage 30:18-23, 2005

11. Cochran DC, Chan MD, Aklilu M, Lovato JF, Alphonse NK, Bourland JD, et al: The effect of targeted agents on outcomes in patients with brain metastases from renal cell carcinoma treated with Gamma Knife surgery. J Neurosurg 116:978983,2012

12. Crossen JR, Garwood D, Glatstein E, Neuwelt EA: Neurobehavioral sequelae of cranial irradiation in adults: a review of radiation-induced encephalopathy. J Clin Oncol 12:627-642, 1994

13. Dagnew E, Kanski J, McDermott MW, Sneed PK, McPherson C, Breneman JC, et al: Management of newly diagnosed single brain metastasis using resection and permanent iodine-125 seeds without initial whole-brain radiotherapy: a two institution experience. Neurosurg Focus 22(3):E3, 2007

14. Dale RG, Jones B, Coles IP: Effect of tumour shrinkage on the biological effectiveness of permanent brachytherapy implants. Br J Radiol 67:639-645, 1994

15. DeAngelis LM, Delattre JY, Posner JB: Radiation-induced dementia in patients cured of brain metastases. Neurology 39:789-796, 1989
16. Do L, Pezner R, Radany E, Liu A, Staud C, Badie B: Resection followed by stereotactic radiosurgery to resection cavity for intracranial metastases. Int J Radiat Oncol Biol Phys 73:486-491, 2009

17. Dritschilo A, Bruckman JE, Cassady JR, Belli JA: Tolerance of brain to multiple courses of radiation therapy. I. Clinical experiences. Br J Radiol 54:782-786, 1981

18. Gans JH, Raper DM, Shah AH, Bregy A, Heros D, Lally BE, et al: The role of radiosurgery to the tumor bed after resection of brain metastases. Neurosurgery 72:317-326, 2013

19. Golas AR, Boyko T, Schwartz TH, Stieg PE, Boockvar JA, Spector JA: Prophylactic plastic surgery closure of neurosurgical scalp incisions reduces the incidence of wound complications in previously-operated patients treated with bevacizumab (Avastin ${ }^{\circledR}$ ) and radiation. J Neurooncol 119:327-331, 2014

20. Hall EJ, Giaccia AJ: Radiobiology for the Radiologist. Philadelphia: Lippincott, 2011, pp 86-101

21. Hashimoto K, Narita Y, Miyakita Y, Ohno M, Sumi M, Mayahara $\mathrm{H}$, et al: Comparison of clinical outcomes of surgery followed by local brain radiotherapy and surgery followed by whole brain radiotherapy in patients with single brain metastasis: single-center retrospective analysis. Int J Radiat Oncol Biol Phys 81:e475-e480, 2011

22. Holt DE, Gill BS, Clump DA, Leeman JE, Burton SA, Amankulor NM, et al: Tumor bed radiosurgery following resection and prior stereotactic radiosurgery for locally persistent brain metastasis. Front Oncol 5:84, 2015

23. Horns J, Webber MM: Retreatment of brain tumors. Radiology 88:322-325, 1967

24. Hsieh J, Elson P, Otvos B, Rose J, Loftus C, Rahmathulla $\mathrm{G}$, et al: Tumor progression in patients receiving adjuvant whole-brain radiotherapy vs localized radiotherapy after surgical resection of brain metastases. Neurosurgery 76:411420, 2015

25. Huang K, Sneed PK, Kunwar S, Kragten A, Larson DA, Berger MS, et al: Surgical resection and permanent iodine-125 brachytherapy for brain metastases. J Neurooncol 91:83-93, 2009

26. Hwang SW, Abozed MM, Hale A, Eisenberg RL, Dvorak T, Yao K, et al: Adjuvant Gamma Knife radiosurgery following surgical resection of brain metastases: a 9-year retrospective cohort study. J Neurooncol 98:77-82, 2010

27. Iwai Y, Yamanaka K, Yasui T: Boost radiosurgery for treatment of brain metastases after surgical resections. Surg Neurol 69:181-186, 2008

28. Jagannathan J, Yen CP, Ray DK, Schlesinger D, Oskouian RJ, Pouratian N, et al: Gamma Knife radiosurgery to the surgical cavity following resection of brain metastases. J Neurosurg 111:431-438, 2009

29. Jarvis LA, Simmons NE, Bellerive M, Erkmen K, Eskey CJ, Gladstone DJ, et al: Tumor bed dynamics after surgical resection of brain metastases: implications for postoperative radiosurgery. Int J Radiat Oncol Biol Phys 84:943-948, 2012

30. Jensen CA, Chan MD, McCoy TP, Bourland JD, deGuzman $\mathrm{AF}$, Ellis TL, et al: Cavity-directed radiosurgery as adjuvant therapy after resection of a brain metastasis. J Neurosurg 114:1585-1591, 2011

31. Kalani MY, Filippidis AS, Kalani MA, Sanai N, Brachman D, McBride HL, et al: Gamma Knife surgery combined with resection for treatment of a single brain metastasis: preliminary results. J Neurosurg 113 Suppl:90-96, 2010

32. Kondziolka D, Niranjan A, Flickinger JC, Lunsford LD: Radiosurgery with or without whole-brain radiotherapy for brain metastases: the patients' perspective regarding complications. Am J Clin Oncol 28:173-179, 2005

33. Kurtz G, Zadeh G, Gingras-Hill G, Millar BA, Laperriere NJ, Bernstein M, et al: Salvage radiosurgery for brain metastases: prognostic factors to consider in patient selection. Int J Radiat Oncol Biol Phys 88:137-142, 2014 
34. Limbrick DD Jr, Lusis EA, Chicoine MR, Rich KM, Dacey RG, Dowling JL, et al: Combined surgical resection and stereotactic radiosurgery for treatment of cerebral metastases. Surg Neurol 71:280-289, 2009

35. Ling CC, Spiro IJ, Mitchell J, Stickler R: The variation of OER with dose rate. Int J Radiat Oncol Biol Phys 11:13671373,1985

36. Loganathan AG, Chan MD, Alphonse N, Peiffer AM, Johnson AJ, McMullen KP, et al: Clinical outcomes of brain metastases treated with Gamma Knife radiosurgery with $3.0 \mathrm{~T}$ versus 1.5 T MRI-based treatment planning: have we finally optimised detection of occult brain metastases? J Med Imaging Radiat Oncol 56:554-560, 2012

37. Maranzano E, Trippa F, Casale M, Costantini S, Anselmo P, Carletti S, et al: Reirradiation of brain metastases with radiosurgery. Radiother Oncol 102:192-197, 2012

38. Mathieu D, Kondziolka D, Flickinger JC, Fortin D, Kenny B, Michaud K, et al: Tumor bed radiosurgery after resection of cerebral metastases. Neurosurgery 62:817-824, 2008

39. McDermott MW, Cosgrove GR, Larson DA, Sneed PK, Gutin PH: Interstitial brachytherapy for intracranial metastases. Neurosurg Clin N Am 7:485-495, 1996

40. Nieder C, Schwerdtfeger K, Steudel WI, Schnabel K: Patterns of relapse and late toxicity after resection and whole-brain radiotherapy for solitary brain metastases. Strahlenther Onkol 174:275-278, 1998

41. Noël G, Proudhom MA, Valery CA, Cornu P, Boisserie G, Hasboun D, et al: Radiosurgery for re-irradiation of brain metastasis: results in 54 patients. Radiother Oncol 60:61-67, 2001

42. Ostertag CB, Kreth FW: Interstitial iodine-125 radiosurgery for cerebral metastases. Br J Neurosurg 9:593-603, 1995

43. Paddick I: A simple scoring ratio to index the conformity of radiosurgical treatment plans. Technical note. J Neurosurg 93 (Suppl 3):219-222, 2000

44. Patel KR, Prabhu RS, Kandula S, Oliver DE, Kim S, Hadjipanayis $\mathrm{C}$, et al: Intracranial control and radiographic changes with adjuvant radiation therapy for resected brain metastases: whole brain radiotherapy versus stereotactic radiosurgery alone. J Neurooncol 120:657-663, 2014

45. Patel KS, Goldenberg B, Schwartz TH: Betadine irrigation and post-craniotomy wound infection. Clin Neurol Neurosurg 118:49-52, 2014

46. Prasad SC, Bassano DA, Fear PI, King GA: Dosimetry of I-125 seeds implanted on the surface of a cavity. Med Dosim 15:217-219, 1990

47. Rogers LR, Rock JP, Sills AK, Vogelbaum MA, Suh JH, Ellis TL, et al: Results of a phase II trial of the GliaSite radiation therapy system for the treatment of newly diagnosed, resected single brain metastases. J Neurosurg 105:375-384, 2006

48. Schulder M, Black PM, Shrieve DC, Alexander E III, Loeffler JS: Permanent low-activity iodine-125 implants for cerebral metastases. J Neurooncol 33:213-221, 1997

49. Shaw E, Scott C, Souhami L, Dinapoli R, Kline R, Loeffler J, et al: Single dose radiosurgical treatment of recurrent previously irradiated primary brain tumors and brain metastases: final report of RTOG protocol 90-05. Int J Radiat Oncol Biol Phys 47:291-298, 2000

50. Shirato H, Takamura A, Tomita M, Suzuki K, Nishioka T, Isu $\mathrm{T}$, et al: Stereotactic irradiation without whole-brain irradiation for single brain metastasis. Int J Radiat Oncol Biol Phys 37:385-391, 1997

51. Sneed PK, Mendez J, Vemer-van den Hoek JGM, Seymour ZA, Ma L, Molinaro AM, et al: Adverse radiation effect after stereotactic radiosurgery for brain metastases: incidence, time course, and risk factors. J Neurosurg 123:373-386, 2015

52. Soltys SG, Adler JR, Lipani JD, Jackson PS, Choi CY, Puataweepong P, et al: Stereotactic radiosurgery of the postop- erative resection cavity for brain metastases. Int J Radiat Oncol Biol Phys 70:187-193, 2008

53. Wernicke AG, Chao KS, Nori D, Parashar B, Yondorf M, Boockvar JA, et al: The cost-effectiveness of surgical resection plus cesium-131 (Cs-131) brachytherapy versus stereotactic radiosurgery versus surgery+whole brain radiotherapy (WBRT) versus WBRT in the treatment of metastatic brain tumors. Neuro Oncol 14 (S6):vi139, 2012 (Abstract)

54. Wernicke AG, Lazow SP, Taube S, Yondorf MZ, Kovanlikaya I, Nori D, et al: Surgical technique and clinically relevant resection cavity dynamics following implantation of cesium-131 brachytherapy in patients with brain metastases. Oper Neurosurg 12:49-60, 2016

55. Wernicke AG, Yondorf MZ, Peng L, Trichter S, Nedialkova L, Sabbas A, et al: Phase I/II study of resection and intraoperative cesium-131 radioisotope brachytherapy in patients with newly diagnosed brain metastases. J Neurosurg 121:338-348, 2014

56. Woo HJ, Hwang SK, Park SH, Hwang JH, Hamm IS: Factors related to the local treatment failure of Gamma Knife surgery for metastatic brain tumors. Acta Neurochir (Wien) 152:1909-1914, 2010

57. Yang R, Wang J, Zhang H: Dosimetric study of Cs-131, I-125, and Pd-103 seeds for permanent prostate brachytherapy. Cancer Biother Radiopharm 24:701-705, 2009

58. Yomo S, Hayashi M: The efficacy and limitations of stereotactic radiosurgery as a salvage treatment after failed whole brain radiotherapy for brain metastases. J Neurooncol 113:459-465, 2013

59. Zamorano L, Yakar D, Dujovny M, Sheehan M, Kim J: Permanent iodine-125 implant and external beam radiation therapy for the treatment of malignant brain tumors. Stereotact Funct Neurosurg 59:183-192, 1992

\section{Disclosures}

Dr. Schwartz reports direct stock ownership in VisionSense and receiving clinical or research support (including equipment or material) from Karl Storz for the study described.

\section{Author Contributions}

Conception and design: Wernicke, Parashar, Pannullo, Stieg, Schwartz. Acquisition of data: Wernicke, Smith, Taube, Yondorf, Parashar, Trichter, Nedialkova, Sabbas, Ramakrishna, Pannullo, Stieg, Schwartz. Analysis and interpretation of data: Wernicke, Smith, Taube, Yondorf, Trichter, Nedialkova, Sabbas, Ramakrishna, Pannullo, Stieg, Schwartz. Drafting the article: Wernicke, Smith, Taube, Schwartz. Critically revising the article: Wernicke, Smith, Taube, Pannullo, Stieg, Schwartz. Reviewed submitted version of manuscript: all authors. Approved the final version of the manuscript on behalf of all authors: Wernicke. Statistical analysis: Christos. Administrative/technical/material support: Wernicke, Smith, Taube, Trichter, Nedialkova, Sabbas, Christos, Ramakrishna, Pannullo, Stieg, Schwartz. Study supervision: Wernicke, Parashar, Ramakrishna, Pannullo, Stieg, Schwartz.

\section{Supplemental Information}

\section{Previous Presentations}

Portions of this paper have been accepted for presentation in 2016 at the 57th Annual Meeting of the American Society for Radiation Oncology (September 25-28, Boston, Massachusetts).

\section{Correspondence}

A. Gabriella Wernicke, Weill Medical College of Cornell University, Stich Radiation Oncology, 525 East 68th St., New York, New York 10065. email: gaw9008@med.cornell.edu. 